\title{
Statins: The Backbone of Treatment of Dyslipidemia
}

\author{
Satyavir Yadav ${ }^{1}$, Sundeep Mishra ${ }^{1}$, Rajeev Agarwala ${ }^{2}$ \\ ${ }^{1}$ All India Institute of Medical Sciences, New Delhi, India \\ ${ }^{2}$ Jaswant Rai Specialty Hospital, Meerut, India
}

Email address:

rajeev_jrsh@yahoo.co.in (R. Agarwala)

\section{To cite this article:}

Satyavir Yadav, Sundeep Mishra, Rajeev Agarwala. Statins: The Backbone of Treatment of Dyslipidemia. American Journal of Internal Medicine. Special Issue: Dyslipidemia: Flash Back and Vision Ahead. Vol. 9, No. 2, 2021, pp. 76-82. doi: 10.11648/j.ajim.20210902.13

Received: September 23, 2020; Accepted: February 8, 2021; Published: March 9, 2021

\begin{abstract}
Statins are a panacea for secondary prevention of atherosclerotic cardiovascular disease and primary prevention in high-risk individuals. They are very well tolerated and side effects like muscle toxicity and increased risk of new onset of diabetes are seen in a minority of cases. They are also recommended in diabetic patient because the benefit is many times more than the risk of diabetes. Statins reduce total cholesterol, LDL cholesterol, Apo B, non-HDL cholesterol, and triglycerides, and also increase high-density lipoprotein (HDL) cholesterol levels in most patients with hypercholesterolemia and combined hyperlipidemia. Statins are not indicated in individuals with Frederickson Class I and V hyperlipidemias. Extensive literature supports use of statins in coronary heart disease (CHD) patients for treatment of dyslipidemia and secondary prevention. It has also been recognized that in secondary prevention and ACS populations lower LDL may be better. Trials have compared moderate with more robust LDL-C reduction, using maximum doses of atorvastatin or simvastatin. Available statins differ in their ability to reduce atherogenic lipoproteins and raise the level of high-density lipoprotein (HDL) cholesterol. Depending on dose used and specific statin, LDL cholesterol reduction of $18 \%$ to $55 \%$ can be expected. Atorvastatin and rosuvastatin are the most potent statins for lowering LDL-C cholesterol levels, yielding average reductions that approach $50 \%$ for atorvastatin and exceed $50 \%$ for rosuvastatin at the highest dose. Reduction in triglycerides with statins ranges from $7 \%$ to $30 \%$, and is higher in hypertriglyceridemic populations and at higher statin doses. HDL levels usually rise by $5 \%$ to $10 \%$. No consistent dose response relationship between statin dose and degree of HDL increase is seen.
\end{abstract}

Keywords: Dyslipidemia, Statin, Atherosclerosis

\section{Background}

Cardiovascular diseases cause 18 million deaths and a similar number of nonfatal cardiovascular events all over the world. [1] Dyslipidemia (LDL-C) account for approximately half the population-attributable risk of myocardial infarction [2] and approximately one quarter of the risk of ischemic stroke. [3]

Multitudinal studies have produced sufficient evidence for a causal relationship between blood cholesterol concentrations and cardiovascular and cerebrovascular disease. [4]

Although there has been noteworthy improvement in atherosclerotic cardiovascular disease (ASCVD) outcomes in recent decades, ASCVD remains the leading cause of morbidity and mortality globally. [4].

The indication for lipid-lowering therapy to prevent cardiovascular disease events in established cardiovascular disease is unambiguous. The benefit of lipid-lowering interventions for cardiovascular disease risk reduction is proven by mendelian randomization studies, prospective epidemiological cohort studies, and randomized trials. [5]

However, the decision on implementing a lipid-lowering intervention in the primary prevention setting is a major challenge in clinical practice for several reasons. Data on the association between the concentrations of the entire range of bloodstream lipids and very long-term cardiovascular outcomes in the general population are rather sparse.

Although HOPE-3 evaluated cholesterol lowering with the use of a low dose of rosuvastatin in a diverse population of persons who did not have cardiovascular disease and who were at intermediate risk. There was a significant reduction 
in the risk of cardiovascular events with the use of rosuvastatin.

New evidence has confirmed that the key initiating event in atherogenesis is the retention of low-density lipoprotein (LDL) cholesterol (LDL-C) and other cholesterol-rich apolipoprotein (Apo) B containing lipoproteins within the arterial wall. Both European and American guidelines recommend that before starting medication in dyslipidemia patients total cardiovascular risk burden needs to be calculated. Prevention of ASCVD in a given person should relate to his or her total $\mathrm{CV}$ risk, the higher the risk, the more intense the action should be. Ideally, risk charts should be based on country-specific cohort data. But unfortunately, these are not available for most countries.

\section{High Blood Cholesterol and ASCVD}

Cholesterol, Lipoproteins, and Apolipoprotein B

Serum cholesterol and its lipoprotein carriers (LDL, very low-density lipoprotein [VLDL], and HDL) are known to be related to ASCVD. LDL-C is the dominant form of atherogenic cholesterol. VLDL is the chief carrier of triglycerides, and VLDL cholesterol (VLDL-C) is also atherogenic. HDL-C is seemingly not atherogenic. Chylomicrons transport dietary fat; chylomicron atherogenicity is uncertain. The combination of LDL-C and VLDL-C is called non-HDL-C and is more atherogenic than either lipoprotein alone. The main protein embedded in LDL and VLDL is apolipoprotein B (apoB), and like nonHDLC, apoB is a stronger indicator of atherogenicity than LDL-C alone. Multiple studies suggest that optimal total cholesterol levels are about $150 \mathrm{mg} / \mathrm{dL}(3.8 \mathrm{mmol} / \mathrm{L})$, which corresponds to an LDL-C level of about $100 \mathrm{mg} / \mathrm{dL}$ (2.6 mmol/L). Adult populations with cholesterol concentrations in this range manifest low rates of ASCVD. $[5,6]$.

Measurement of LDL-C

The standard calculation method for LDL-C is the

Friedewald formula: LDL-C $=(\mathrm{TC})-($ triglycerides $/ 5)-($ HDL-C $)$

When triglyceride levels are not elevated, this equation is sufficiently accurate. In hypertriglyceridemia, however, Friedewald-calculated LDLC can be erroneous. In these cases measuring Apolipoprotein B is helpful.

Effect of food intake on cholesterol levels:

After normal food intake, LDL-C differs minimally with time. Fasting and nonfasting TC and HDL-C levels appear to have fairly similar prognostic value and associations with CVD outcomes. Thus, nonfasting samples can be used for risk assessment in primary prevention and for assessment of baseline LDL-C levels before the initiation of a statin in primary and secondary prevention. [7] In adults with a family history of premature ASCVD or genetic hyperlipidemia, a fasting lipid profile is reasonable for initial evaluation. The unreliability of the Friedewald-calculated LDL-C levels rise at lower levels of LDL-C.

Measurements of Apolipoprotein B and Lipoprotein (a)
Two lipoprotein entities related to LDL-C are apoB and lipoprotein (a) $[\mathrm{Lp}(\mathrm{a})]$. Because $\mathrm{apoB}$ is the major apolipoprotein embedded in LDL and VLDL, several investigators identify strength of association between apoB and ASCVD. Others report a high correlation between apoB and non-HDL-C. Under certain circumstances, particularly in patients with hypertriglyceridemia, the measurement of apoB may have advantages. Nevertheless, apoB measurement carries extra expense, and its measurement in some laboratories may not be reliable. A relative indication for its measurement would be triglyceride $\geq 200 \mathrm{mg} / \mathrm{dL}$. A level $>130 \mathrm{mg} / \mathrm{dL}$ corresponds to an LDL-C level $\geq 160 \mathrm{mg} / \mathrm{dL}$ and constitutes a risk-enhancing factor. [8]

$\mathrm{Lp}$ (a) measurement should be considered at least once in each adult person's lifetime to identify those with very high inherited Lp(a) levels $>180 \mathrm{mg} / \mathrm{dL}$ ( $>430 \mathrm{nmol} / \mathrm{L})$ who may have a lifetime risk of ASCVD equivalent to the risk associated with heterozygous familial hypercholesterolemia.

Risk stratification for management of dyslipidemia

The general Framingham CVD risk score is being used by American Guidelines for management of blood cholesterol, adults are categorized as having low $(<5 \%)$, borderline $(5 \%$ to $<7.5 \%)$, intermediate $(7.5 \%$ to $<20 \%)$, or high $(>20 \%) 10$ year risk. [9]

The Europeans uses The SCORE (Systematic Coronary Risk Estimation) system. The 2016 European Society of Cardiology/European Atherosclerosis Society Guidelines for the management of dyslipidemias and the 2016 European Guidelines on cardiovascular disease prevention in clinical practice, in that: (i) age has been extended from age 65 to 70 ; (ii) the interaction between age and each of the other risk factors has been incorporated, thus reducing the overestimation of risk in older persons in the original Systematic Coronary Risk Estimation charts; and (iii) the cholesterol band of $8 \mathrm{mmol} / \mathrm{L}$ has been removed since such persons will qualify for further evaluation in any event.

Familial dyslipidemias

Plasma lipid levels are, to a very large extent, determined by genetic factors. In its more extreme forms this is manifested as familial dyslipidemias. Among these, FH is the most common and is strongly related to CVD (Table 1).

\subsection{Familial Combined Hyperlipidemia}

The combination of ApoB $>120 \mathrm{mg} / \mathrm{dL}$ and $\mathrm{TGs}>1.5$ $\mathrm{mmol} / \mathrm{L}(>133 \mathrm{mg} / \mathrm{dL})$ with a family history of premature CVD can be used to identify people who most probably have FCH. [10]

\subsection{Familial Hypercholesterolaemia}

\subsubsection{Heterozygous Familial Hypercholesterolaemia}

It causes premature CVD due to lifelong elevation of plasma levels of LDL-C. If left untreated, men and women with $\mathrm{HeFH}$ typically develop early CAD before the ages of 55 and 60 years respectively. The risk of CHD among individuals with definite or probable $\mathrm{HeFH}$ is estimated to be 
increased at least 10 -fold.

Cholesterol-lowering treatment should be initiated as soon as possible after a diagnosis has been made.

\subsubsection{Homozygous Familial Hypercholesterolaemia}

$\mathrm{HoFH}$ is a rare and life-threatening disease. The clinical picture is characterized by extensive xanthomas, marked premature and progressive $\mathrm{CVD}$, and TC $>13 \mathrm{mmol} / \mathrm{L}$ ( $>500$ $\mathrm{mg} / \mathrm{dL}$ ). Most patients develop CAD and aortic stenosis before the age of 20 years and die before 30 years of age. The patients should be treated with intensive LDL-lowering drug therapy and, when available, with lipoprotein apheresis. This treatment (every 1-2 weeks) can decrease plasma LDL-C levels by $55-70 \%$. [11]

\subsubsection{Familial Hypercholesterolaemia in Children}

$\mathrm{FH}$ is diagnosed in children based on phenotypic criteria including elevated LDL-C plus a family history of elevated LDL-C, premature CAD, and/or positive genetic testing. [12]

Treatment of children with FH includes a healthy lifestyle and statin treatment. A heart-healthy diet should be adopted early in life and statin treatment should be considered at 6-10 years of age. Statin treatment should be started with low doses and the dose should be increased to reach goals.

\subsection{Familial Dysbetalipoproteinaemia}

It produces a characteristic clinical syndrome in which both TC and TGs are elevated before treatment, usually both in the range of $7-10 \mathrm{mmol} / \mathrm{L}$. In severe cases, patients develop tuberoeruptive xanthomas, particularly over the elbows and knees, and palmar xanthomata in the skin creases of the hands and wrists. The risk of CAD is very high, and accelerated atherosclerosis of the femoral and tibial arteries is also prevalent.

Most cases respond well to treatment with a statin or, if dominated by high TGs, a fibrate; often a combination of a statin and a fibrate may be needed.

Action to prevent acute pancreatitis in severe hypertriglyceridaemia

The risk of pancreatitis is clinically significant if TGs are $>10 \mathrm{mmol} / \mathrm{L}(880 \mathrm{mg} / \mathrm{dL})$, particularly when occurring in association with familial chylomicronaemia, and actions to prevent acute pancreatitis are mandatory. $[13,14]$

Restriction of calories and fat content (10-15\% recommended) in the diet, and alcohol abstinence are obligatory. Fibrate therapy (fenofibrate) should be initiated, with n-3 fatty acids (2-4 g/day) as adjunct therapy. Lomitapide may also be considered in severe cases. In patients with DM, insulin therapy should be initiated to achieve good glycaemic control. In general, a sharp decrease of TG values is seen within 2-5 days. In the acute setting, plasmapheresis is able to rapidly lower TG levels. Volanesorsen has been recently approved by the EMA as an adjunct to diet in adult patients with genetically confirmed Familial Chylomicronemia Syndrome (FCS) who are at highrisk for pancreatitis.

\section{Therapeutic Modalities}

\subsection{Diet Composition, Weight Control, and Physical Activity}

Patients should consume a dietary pattern that emphasizes intake of vegetables, fruits, whole grains, legumes, healthy protein sources (low-fat dairy products, low-fat poultry (without the skin), fish/seafood, and nuts), and non-tropical vegetable oils; and limit intake of sweets, sugar-sweetened beverages and red meats. This dietary pattern should be adjusted to appropriate calorie requirements, personal and cultural food preferences, and nutritional therapy for other medical conditions including diabetes. In general, adults should be advised to engage in aerobic physical activity 3-4 sessions per week, lasting on average 40 minutes per session and involving moderate-to vigorous-intensity physical activity.

\subsection{Lipid-Lowering Drugs}

Among lipid-lowering drugs, statins are the cornerstone of therapy, in addition to healthy lifestyle interventions. Other LDL-lowering drugs include ezetimibe, bile acid sequestrants, and PCSK9 inhibitors. Triglyceride-lowering drugs are fibrates and niacin; they have a mild LDL lowering action, but RCTs do not support their use as add-on drugs to statin therapy. [15]

\subsubsection{Statin Therapy}

The intensity of statin therapy is divided into 3 categories: high-intensity, moderate-intensity, and low intensity. [16] High-intensity statin therapy typically lowers LDL-C levels by $\geq 50 \%$, moderate-intensity statin therapy by $30 \%$ to $49 \%$, and low-intensity statin therapy by $<30 \%$ (Table 4 ).

Monitoring response of $L D L-C$ to statin therapy:

In large RCTs of cholesterol-lowering therapy, LDL-C lowering has been consistently shown to reduce the risk of ASCVD. One large meta-analysis of statin clinical trials showed a progressive reduction in risk of major ASCVD events with lower on-treatment LDL-C levels. In another larger meta-analysis of 14 statin trials, it was observed that a $38.7-\mathrm{mg} / \mathrm{dL}(1-\mathrm{mmol} / \mathrm{L})$ reduction of LDL-C levels is accompanied by a $21 \%$ reduction in ASCVD risk.

As a rough guide, a lowering of LDL-C levels of $1 \%$ gives an approximate $1 \%$ reduction in the risk of ASCVDsomewhat more at higher baseline LDL-C levels and somewhat less at lower baseline levels. [17]

\subsubsection{Nonstatin Therapies}

Ezetimibe is the most commonly used nonstatin agent. It lowers LDL-C levels by $13 \%$ to $20 \%$ and has a low incidence of side effects. Bile acid sequestrants reduce LDL-C levels by $15 \%$ to $30 \%$ depending on the dose. Bile acid sequestrants are not absorbed and do not cause systemic side effects, but they are associated with gastrointestinal complaints (eg, constipation) and can cause severe hypertriglyceridemia when fasting triglycerides are $\geq 300 \mathrm{mg} / \mathrm{dL}(\geq 3.4 \mathrm{mmol} / \mathrm{L})$. PCSK9 inhibitors are powerful LDL-lowering drugs. They 
generally are well tolerated. [18]

\subsubsection{Nonstatin Add-on Drugs to Statin Therapy}

Under certain circumstances, nonstatin medications (ezetimibe, bile acid sequestrants, and PCSK9 inhibitors) may be useful in combination with statin therapy. The addition of a bile acid sequestrant or ezetimibe to a statin regimen increases the magnitude of LDL-C lowering by approximately $15 \%$ to $30 \%$ and $13 \%$ to $20 \%$, respectively. The addition of a PCSK9 inhibitor to a statin regimen has been shown to further reduce LDL-C levels by $43 \%$ to $64 \%$.

\subsubsection{ACC Recommendation}

As a primary recommendation, high intensity statin therapy is indicated for clinical ASCVD, but if this cannot be used, moderate-intensity statin therapy can be initiated. The first goal is to achieve a $\geq 50 \%$ reduction in LDL-C levels, but if LDL-C levels remains $\geq 70 \mathrm{mg} / \mathrm{dL}(\geq 1.8 \mathrm{mmol} / \mathrm{L})$ on maximally tolerated statin therapy, adding ezetimibe may be reasonable. In patients $>75$ years of age with ASCVD, potential benefits versus adverse effects of statin therapy should be considered before initiation of statin therapy.

\subsubsection{Statin Safety and Statin Associated Side Effects}

Statin therapy is usually well tolerated and safe. As with other classes of medications, associated side effects are seen. Instead of the label statin intolerance, the present guideline prefers statin-associated side effects because the large majority of patients are able to tolerate statin rechallenge with an alternative statin or alternative regimen, such as reduced dose or in combination with non statins.

The most frequent are SAMS. SAMS usually are subjective myalgia, reported observationally in $5 \%$ to $20 \%$ of patients. SAMS often result in nonadherence and can adversely impact ASCVD outcomes. [19, 20]

Statins modestly increase risk of incident diabetes mellitus in susceptible individuals, but this should not be the cause for discontinuation.

\subsubsection{Drug Interactions}

Drugs potentially interacting with statins metabolized by cytochrome P450 3A4 leading to increased risk of myopathy and rhabdomyolysis are summarized in Table 5.

Patients on statin treatment have been shown to exhibit an increased risk of dysglycemia and development of type 2 diabetes mellitus (T2DM). Several studies have shown that this is a consistent, dose-related effect. A minor, not clinically relevant elevation of glycated hemoglobin ( $\mathrm{HbA} 1 \mathrm{c})$ has also been observed. The number needed to cause one case of diabetes has been estimated as 255 over 4 years of statin treatment.

However, the risk is higher with the more potent statins at high doses, and is also higher in the elderly, and in the presence of other risk factors for diabetes such as overweight or insulin resistance. Overall, the absolute reduction in the risk of CVD in high-risk patients clearly outweighs the possible adverse effects of a small increase in the incidence of diabetes. [21, 22] This effect is probably related to the mechanism of action of statins, as Mendelian randomization studies have confirmed the increased risk of $\mathrm{DM}$ in individuals with HMG-CoA reductase polymorphisms that reduce cholesterol synthesis.

\subsection{Management of Dyslipidemia}

Treatment goals according to European guidelines for lowdensity lipoprotein cholesterol across categories of total cardiovascular disease risk are summarized in Table 2.

Adults 40 to 75 years of age in primary prevention can be classified as borderline risk (10-year risk of ASCVD $(5 \%$ to $<7.5 \%)$, intermediate-risk $(7.5 \%$ to $<20 \%)$, and high-risk $(20 \%)$. For intermediate-risk patients, moderate- to highintensity statin therapy should be considered during risk discussion of treatment options. Additional considerations favoring use of statins in intermediate-risk patients include other independent risk conditions and, in selected individuals, risk-enhancing factors associated with greater ASCVD risk. The statin eligibility criteria for primary prevention according to 5 major ASCVD guidelines are outlined in Table 3.

\subsubsection{Treatment of Dyslipidemias in Older People}

Treatment with statins is recommended for primary prevention, according to the level of risk, in older people aged $<75$. Initiation of statin treatment for primary prevention in older people aged $>75$ may be considered, if at high risk or above.

\subsubsection{Treatment of Dyslipidemias in DM}

In patients with T2DM at very-high risk, an LDL-C reduction of $>50 \%$ from baseline and an LDL-C goal of $<1.4$ $\mathrm{mmol} / \mathrm{L}(<55 \mathrm{mg} / \mathrm{dL})$ is recommended. In patients with T2DM at high risk, an LDL-C reduction of $>50 \%$ from baseline and an LDL-C goal of $<1.8 \mathrm{mmol} / \mathrm{L}(<70 \mathrm{mg} / \mathrm{dL})$ is recommended. Statins are recommended in patients with T1DM who are at high or very-high risk. Intensification of statin therapy should be considered before the introduction of combination therapy. If the goal is not reached, statin combination with ezetimibe should be considered. Statin therapy is not recommended in pre-menopausal patients with DM who are considering pregnancy or not using adequate contraception.

The most important way to prevent ASCVD is to promote a healthy lifestyle throughout life. Prevention strategies must include a strong focus on lifestyle optimization (improvements in diet, physical activity, and avoidance of tobacco use and exposure to second hand smoke) to minimize the risk of future ASCVD events.

In adults at intermediate risk $(>7.5 \%$ to $<20 \% 10$-year ASCVD risk) or selected adults at borderline risk (5\% to $<7.5 \%$ 10-year ASCVD risk), risk-based decisions for preventive interventions (e.g., statin therapy) remain uncertain, it is reasonable to measure a coronary artery calcium score to guide clinician-patient risk discussion.

Statin therapy is first-line treatment for primary prevention of ASCVD in patients with elevated low density lipoprotein 
cholesterol levels ( $>190 \mathrm{mg} / \mathrm{dL}$ ), those with diabetes mellitus, who are 40 to 75 years of age, and those determined to be at sufficient ASCVD risk after a clinician-patient risk discussion.

\subsubsection{Management of Dyslipidemia in Women}

Statin treatment is recommended for primary prevention of ASCVD in high-risk women. Statins are recommended for secondary prevention in women with the same indications and goals as in men.

Lipid-lowering drugs should not be given when pregnancy is planned, during pregnancy, or during the breastfeeding period. However, for severe $\mathrm{FH}$ patients, bile acid sequestrants (which are not absorbed) and/or LDL apheresis may be considered.

\subsubsection{Severe Hypercholesterolemia}

(LDL-C $\geq 190 \mathrm{mg} / \mathrm{dL}[\geq 4.9 \mathrm{mmol} / \mathrm{L}]$ )

Patients with severe hypercholesterolemia have a high lifetime risk, and decisions about statins in these patients do not require ASCVD risk scoring. These patients derive net ASCVD risk reduction benefit from interventions that increase expression of LDL receptors. In selected patients with severe hypercholesterolemia whose LDL-C is inadequately controlled with drug therapy, LDL apheresis is an option.

\section{Conclusion}

Statins are proven agents for prevention of atherosclerotic cardiovascular disease and are recommended by all Guidelines throughout the globe. Statins are powered to reduce LDL-C by $1 \mathrm{mmol} / \mathrm{L}$ and this translates into reduction of cardiovascular events by 20 to $24 \%$. If the LDL goals are not achieved with statins, non statins drugs like ezetimibe, bempedoic acid and PCSK-9 inhibitors are utilized.

Table 1. Genetic disorders of lipoprotein metabolism.

\begin{tabular}{|c|c|c|c|}
\hline Disorder & Prevalence & Gene (s) & Effect on lipoproteins \\
\hline \multirow{3}{*}{$\mathrm{HeFH}$} & \multirow{3}{*}{1 in $200-250$} & LDLR & \\
\hline & & APO B & Increased LDL-C \\
\hline & & PCSK9 & \\
\hline \multirow{3}{*}{ HoFH } & \multirow{3}{*}{$\begin{array}{l}1 \text { in } 160000-320 \\
000\end{array}$} & LDLR & \multirow{3}{*}{ Increased LDL-C } \\
\hline & & APO B & \\
\hline & & PCSK9 & \\
\hline $\mathrm{FCH}$ & 1 in $100-200$ & USF1 $\mathrm{p}+$ modifying genes & Increased LDL-C, VLDL-Cand ApoB \\
\hline Familial dysbetalipoproteinaemia & 1 in 5000 & APO E & Increased IDL and chylomicron remnants \\
\hline $\begin{array}{l}\text { Familial lipoprotein lipase deficiency } \\
\text { (familial chylomicron syndrome) }\end{array}$ & 2 in 106 & $\begin{array}{l}\text { LPL } \\
\text { APO C2 ApoAVGPIHBP1 } \\
\text { LMF1 }\end{array}$ & Increased chylomicrons and VLDL-C \\
\hline Tangier disease (analphalipoproteinaemia) & 1 in 106 & ABCA1 & Decreased HDL-C \\
\hline Familial LCAT deficiency & 1 in 106 & LCAT & Decreased HDL-C \\
\hline
\end{tabular}

Apo=apolipoprotein; $\quad \mathrm{FCH}=$ familial combined hyperlipidaemia; $\quad \mathrm{HDL}-\mathrm{C}=$ high-density lipoprotein $\quad$ cholesterol; HeFH=heterozygous familial hypercholesterolaemia; HoFH=homozygous familial hypercholesterolaemia; IDL=intermediate-density lipoprotein; LCAT=lecithin cholesterol acyltransferase; LDL-C=low-density lipoprotein cholesterol; VLDL=very low-density lipoprotein cholesterol

Table 2. Treatment goals for low-density lipoprotein cholesterol across categories of total cardiovascular disease risk.

\begin{tabular}{|c|c|}
\hline Category & Treatment Goals (LDL-C mg/dl) \\
\hline Low Risk SCORE $<1 \%$ & \multirow[t]{2}{*}{116} \\
\hline Moderate SCORE $\geq 1 \%$ and $<5 \%$ & \\
\hline •Young patients (T1DM <35 years; & \multirow{6}{*}{100} \\
\hline $\mathrm{T} 2 \mathrm{DM}<50$ years) with $\mathrm{DM}$ duration & \\
\hline$<10$ years without other risk factors & \\
\hline High SCORE $\geq 5 \%$ and $<10 \%$ & \\
\hline -Markedly elevated single risk factor & \\
\hline$(310 \mathrm{mg} / \mathrm{dL})$ or LDL-C $>4.9 \mathrm{mmol} / \mathrm{L}$ & \\
\hline$(190 \mathrm{mg} / \mathrm{dL})$ or $\mathrm{BP} \geq 180 / 110 \mathrm{mmHg}$ & \multirow{4}{*}{70} \\
\hline -FH without other major risk factors & \\
\hline -Moderate CKD (eGFR 30-59 mL/mi & \\
\hline $\begin{array}{l}\text {-DM w/o target organ damage, withD } \\
\text { additional risk factor }\end{array}$ & \\
\hline Very High •ASCVD (clinical/imaging) & \multirow{7}{*}{55} \\
\hline$\cdot S C O R E \geq 10 \%$ & \\
\hline •FH with ASCVD or with another & \\
\hline $\begin{array}{l}\text { major risk factor } \\
\text { •Severe CKD }(\mathrm{eGFR}<30 \mathrm{~mL} / \mathrm{min})\end{array}$ & \\
\hline DM \& target organ damage: $\geq 3$ & \\
\hline major risk factors; or early onset of & \\
\hline T1DM of long duration $(>20$ years & \\
\hline
\end{tabular}


Table 3. Statin Eligibility Criteria According to 5 Major ASCVD Primary Prevention Guidelines.

\begin{tabular}{|c|c|c|c|c|c|}
\hline Criteria & NICE & USPSTF & CCS & ESC/EAS & АСС/AНA \\
\hline Lipid-based & $\begin{array}{l}\text { Cholesterol level } \\
\text { LDL-C }>190 \mathrm{mg} / \mathrm{dL} \\
\text { or } \mathrm{TC}>290 \mathrm{mg} / \mathrm{dL}\end{array}$ & NA & LDL-C $\geq 193 \mathrm{mg} / \mathrm{dL}$ & $\begin{array}{l}\mathrm{LDL}-\mathrm{C}>232 \mathrm{mg} / \mathrm{dL} \text { or } \\
\mathrm{TC}>309 \mathrm{mg} / \mathrm{dL}\end{array}$ & $\begin{array}{l}\mathrm{LDL}-\mathrm{C} \geq 190 \mathrm{mg} / \mathrm{dL} \text { or } \\
{[\mathrm{TG}>2.3 \mathrm{mmol} / \mathrm{L}(200} \\
\mathrm{mg} / \mathrm{dL})] .\end{array}$ \\
\hline $\begin{array}{l}\text { Risk-based } \\
\text { Age range, yrs }\end{array}$ & $40-75$ & $40-75$ & $40-75$ & $40-65$ & 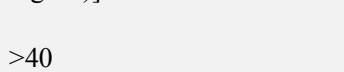 \\
\hline Eligibility & $\begin{array}{l}\text { QRISK2 } \geq 10 \% \\
\text { predicted } 10-y \text { risk } \\
\text { of any ASCVD or } \\
\text { nondialysis-- } \\
\text { dependent CKD }\end{array}$ & $\begin{array}{l}\text { PCE } \geq 10 \% \\
\text { predicted } 10-y \\
\text { risk of any } \\
\text { ASCV plus } \geq 1 \\
\text { CVD risk factor }\end{array}$ & $\begin{array}{l}\text { FRS } \geq 20 \% \text { predicted } 10-y \\
\text { risk of any ASCVD or age } \\
40-75 \mathrm{y} ; \mathrm{FRS} \geq 10 \% \text { to } \\
<20 \% \text { predicted } 10 \text {-y risk } \\
\text { of any ASCVD; LDL-C } \\
\geq 135 \\
\mathrm{mg} / \mathrm{dLb} \text { or diabetes or } \\
\mathrm{CKD} \\
(\text { age } \geq 50 \mathrm{y}) \text { and eGFR } \\
\text { level } \\
<60 \mathrm{~mL} / \mathrm{min} / 1.73 \mathrm{~m} 2\end{array}$ & $\begin{array}{l}\text { LDL-C level } \geq 155 \mathrm{mg} / \mathrm{dL} \text {; } \\
\text { SCORE } 5 \% \text { to }<10 \% \\
\text { predicted } 10 \text {-y risk of fatal } \\
\text { ASCVD or age } 40-65 \mathrm{y} ; \\
\text { LDL-C } \geq 97 \mathrm{mg} / \mathrm{dL} ; \\
\text { SCORE } \\
\geq 10 \% \text { predicted } 10 \text {-y risk } \\
\text { of fatal ASCVD or } \\
\text { diabetes; } \\
\text { or nondialysis-dependent } \\
\text { CKD and eGFR level }<60 \\
\mathrm{~mL} / \mathrm{min} / 1.73 \mathrm{~m} 2\end{array}$ & $\begin{array}{l}\text { PCE } \geq 7.5 \% \text { predicted } 10-y \\
\text { risk of any ASCVD; LDL-C } \\
70-189 \mathrm{mg} / \mathrm{dL} \text { or diabetes } \\
\text { (plus LDL-C level } \geq 70 \\
\text { mg/dL); risk-enhancers : } \\
\text { family history of ASCVD, } \\
\text { persistently elevated LDL-C } \\
\text { levels } \geq 160 \mathrm{mg} / \mathrm{dL}, \mathrm{CKD}, \\
\text { metabolic syndrome, } \\
\text { persistently elevated } \\
\text { triglycerides } \geq 175 \mathrm{mg} / \mathrm{dL}, \text { hs- } \\
\text { CRP levels } \geq 2.0 \mathrm{mg} / \mathrm{dL} ; \\
\text { Lp(a) levels }>50 \mathrm{mg} / \mathrm{dL}, \text { apoB } \\
\text { levels } \geq 130 \mathrm{mg} / \mathrm{dL}, \text { and } \\
\text { ankle-brachial index }<0.9\end{array}$ \\
\hline
\end{tabular}

Table 4. High, Moderate and Low-Intensity Statin Therapy Percent LDL-C reductions with the primary statin medications use.

\begin{tabular}{llll}
\hline & High Intensity & Moderate Intensity & Low Intensity \\
\hline LDL-C lowering & $\geq 50 \%$ & $30 \%-49 \%$ & $<30 \%$ \\
& & Atorvastatin $10 \mathrm{mg}$ & \\
& Atorvastatin & $(20 \mathrm{mg})$ & Simvastatin \\
Statins & Rosuvastatin $(5 \mathrm{mg})$ & $10 \mathrm{mg}$ \\
& Rosuvastatin 20 & $10 \mathrm{mg}$ & \\
mg $(40 \mathrm{mg})$ & Simvastatin $20-40$ & Pravastatin \\
& & mg & $10-20 \mathrm{mg}$ \\
& Pravastatin $40 \mathrm{mg}$ & Lovastatin 20 \\
& (80 mg) & mg \\
& Lovastatin $40 \mathrm{mg}$ & Fluvastatin \\
& (80 mg) & $20-40 \mathrm{mg}$ \\
\hline
\end{tabular}

Table 5. Drugs potentially interacting with statins metabolized by cytochrome P450 3 A4 leading to increased risk of myopathy and rhabdomyolysis.

\begin{tabular}{lll}
\hline Anti-infective agents & Calcium antagonists & Other \\
\hline Itraconazole & Verapamil & Amiodarone \\
Ketoconazole & Diltiazem & Cyclosporine \\
Posaconazole & Amlodipine & Danazol \\
Erythromycin & & Ranolazine \\
Clarithromycin & & Gemfibrozil \\
Telithromycin & & Grapefruit juice \\
\hline
\end{tabular}

\section{References}

[1] GBD 2013 Risk factors Collaborators. Global, regional, and national comparative risk assessment of 79 behavioral, environmental and occupational, and metabolic risks or clusters of risks in 188 countries, 1990-2013: a systematic analysis for the Global Burden of Disease Study 2013. Lancet2015; 386: 2287-2323.

[2] Yusuf S, Hawken S, Ounpuu S, et al. Effect of potentially modifiable risk factors associated with myocardial infarction in 52 countries (the INTERHEART study): case-control study. Lancet 2004; 364: 937-52.
[3] O'Donnell MJ, Xavier D, Liu L, et al. Risk factors for ischaemic and intracerebral haemorrhagic stroke in 22 countries (the INTERSTROKE study): a case-control study. Lancet 2010; 376: 112-23.

[4] Weir HK, Anderson RN, Coleman King SM, et al. Heart disease and cancer deaths - trends and projections in the United States, 1969-2020. Prev Chronic Dis. 2016; 13: E157.

[5] Stamler J, Wentworth D, Neaton JD. Is relationship between serum cholesterol and risk of premature death from coronary heart disease continuous and graded? Findings in 356222 primary screenees of the Multiple Risk Factor Intervention Trial (MRFIT) JAMA. 1986; 256: 2823-8. 
[6] Kannel WB, Castelli WP, Gordon T, et al. Serum cholesterol, lipoproteins, and the risk of coronary heart disease. The Framingham study. Ann Intern Med. 1971; 74: 1-12.

[7] Nordestgaard BG, Langsted A, Mora S, et al. Fasting is not routinely required for determination of a lipid profile: clinical and laboratory implications including flagging at desirable concentration cut-points - a joint consensus statement from the European Atherosclerosis Society and European Federation of Clinical Chemistry and Laboratory Medicine. Eur Heart J. 2016; 37: 1944-58.

[8] Grundy SM, Vega GL, Tomassini JE, et al. Comparisons of apolipoprotein B levels estimated by immunoassay, nuclear magnetic resonance, vertical auto profile, and non-high-density lipoprotein cholesterol in subjects with hypertriglyceridemia (SAFARI Trial). Am J Cardiol. 2011; 108: 40-6.

[9] Grundy SM, Stone NJ, Bailey AL, et al. 2018 AHA/ACC /AACVPR/ AAPA/ABC/ ACPM/ADA/ AGS/APhA/ ASPC/NLA/PCNA guideline on the management of blood cholesterol: a report of the American College of Cardiology/American Heart Association Task Force on Clinical Practice Guidelines. J Am Coll Cardiol. 2018 Nov 10 [E-pub ahead of print].

[10] Veerkamp MJ, de Graaf J, Bredie SJ, Hendriks JC, Demacker PN, Stalenhoef AF. Diagnosis of familial combined hyperlipidemia based on lipid phenotype expression in 32 families: results of a 5-year follow-up study. Arterioscler Thromb VascBiol 2002; 22: 274-282.

[11] Cuchel M, Bruckert E, Ginsberg HN, Raal FJ, Santos RD, Wiklund O, Chapman MJ, et al. European Atherosclerosis Society Consensus Panel on Familial Hypercholesterolaemia. Homozygous familial hypercholesterolaemia: new insights and guidance for clinicians to improve detection and clinical management. A position paper from the Consensus Panel on Familial Hypercholesterolaemia of the European Atherosclerosis Society. Eur HeartJ2014; 35: 2146-2157.

[12] Wiegman A, Gidding SS, Watts GF, Chapman MJ, Ginsberg HN, Cuchel M, et al. European Atherosclerosis Society Consensus Panel. Familial hypercholesterolaemia in children and adolescents: gaining decades of life by optimizing detection and treatment. Eur Heart J 2015; 36: 2425-2437.

[13] Moulin P, Dufour R, Averna M, Arca M, Cefalu AB, Noto D, D'Erasmo L, Di Costanzo A, Marcais C, Alvarez-Sala Walther LA, Banach M, Boren J, Cramb R, Gouni-Berthold I, Hughes
E, Johnson C, Pinto X, Reiner Z, van Lennep JR, Soran H, Stefanutti C, Stroes E, Bruckert E. Identification and diagnosis of patients with familial chylomicronaemia syndrome (FCS): expert panel recommendations and proposal of an "FCS score". Atherosclerosis 2018; 275: 265_272.

[14] Meyers CD, Tremblay K, Amer A, Chen J, Jiang L, Gaudet D. Effect of the DGAT1 inhibitor pradigastat on triglyceride and apoB48 levels in patients with familial chylomicronemia syndrome. Lipids Health Dis 2015; 14: 8.

[15] Miller M, Stone NJ, Ballantyne C, et al. Triglycerides and cardiovascular disease: a scientific statement from the American Heart Association. Circulation. 2011; 123: 2292333.

[16] Stone NJ, Robinson JG, Lichtenstein AH, et al. 2013 ACC/AHA guideline on the treatment of blood cholesterol to reduce atherosclerotic cardiovascular risk in adults: a report of the American College of Cardiology/American Heart Association Task Force on Practice Guidelines. Circulation. 2014; 129: S1-45.

[17] Amarenco P, Bogousslavsky J, Callahan A 3rd, et al. Highdose atorvastatin after stroke or transient ischemic attack. N Engl J Med. 2006; 355: 549-59.

[18] Cannon CP, Blazing MA, Giugliano RP, et al. Ezetimibe added to statin therapy after acute coronary syndromes. N Engl J Med. 2015; 372: 2387-97.

[19] Parker BA, Capizzi JA, Grimaldi AS, et al. Effect of statins on skeletal muscle function. Circulation. 2013; 127: 96-103.

[20] Navarese EP, Buffon A, Andreotti F, et al. Meta-analysis of impact of different types and doses of statins on new-onset diabetes mellitus. Am J Cardiol. 2013; 111: 1123-30.

[21] Preiss D, Seshasai SR, Welsh P, Murphy SA, Ho JE, Waters DD, DeMicco DA, Barter P, Cannon CP, Sabatine MS, Braunwald E, Kastelein JJ, de Lemos JA, Blazing MA, Pedersen TR, Tikkanen MJ, Sattar N, Ray KK. Risk of incident diabetes with intensive-dose compared with moderate-dose statin therapy: a metaanalysis. JAMA 2011; 305: 2556-2564.

[22] Waters DD, Ho JE, Boekholdt SM, DeMicco DA, Kastelein JJ, Messig M, Breazna A, Pedersen TR. Cardiovascular event reduction versus new-onset diabetes during atorvastatin therapy: effect of baseline risk factors for diabetes. J Am Coll Cardiol 2013; 61: 148-152. 